\title{
Long-acting reversible contraception utilization and associated factors among women in extended postpartum period in southern Ethiopia
}

Yibeltal Mesfin ${ }^{1 *}$ (D) and Abraham Wallelign²

\begin{abstract}
Background: Postpartum long-acting reversible contraceptive is important to prevent unintended and closed spaced pregnancy following the first 12 months of childbirth. Few data were available on postpartum long-acting reversible contraceptive use in Ethiopia. So, this study aimed to assess the long-acting reversible contraception use and associated factors among women who gave birth in the last 12 months.

Methods: A community-based cross-sectional study was conducted from October 1st to November 2019. Systematic random sampling was applied to recruit a total of 416 study participants. Data were collected using a structured questionnaire. Data were entered using Epidata 4.6 and exported to SPSS version 25 for analysis. P-value $<0.05$ with 95\% confidence interval (Cl) used to declare statistical significance.

Result: In this study, long acting contraceptive utilization among women in the extended postpartum period was 22.6\%. Maternal age $\leq 24$ years ( $A O R=3.7,95 \% \mathrm{Cl}: 1.5,8.9)$, being married ( $\mathrm{AOR}=3.595 \% \mathrm{Cl}$ : $(1.17-10.28)$ ), menses resumption ( $\mathrm{AOR}=4.995 \% \mathrm{Cl}:(2.92,8.20)$ ), sexual intercourse resumption $(\mathrm{AOR}=7.195 \% \mathrm{Cl}:(4.03,12.56))$ and received postpartum family planning counseling $(A O R=3.295 \%(1.95,5.28))$ were the factors associated with Longacting reversible contraception use.

Conclusion: This finding showed postpartum women's long-acting reversible contraceptive use during the extended postpartum period was low. The factors significantly associated with extended postpartum modern contraceptive use were women's age, being married, menses resumption, sexual intercourse resumption, and got postnatal family planning counseling. Strengthening Antenatal and postnatal counseling of postpartum family planning would improve long-acting reversible contraception use.
\end{abstract}

Keywords: Extended postpartum period, Long-acting reversible contraception, Postpartum women

* Correspondence: hazardkuku@gmail.com

'Department of Midwifery, College of medicine and health sciences, Wolkite University, Wolkite, Ethiopia

Full list of author information is available at the end of the article

C C The Author(s). 2021 Open Access This article is licensed under a Creative Commons Attribution 4.0 International License, which permits use, sharing, adaptation, distribution and reproduction in any medium or format, as long as you give appropriate credit to the original author(s) and the source, provide a link to the Creative Commons licence, and indicate if changes were made. The images or other third party material in this article are included in the article's Creative Commons licence, unless indicated otherwise in a credit line to the material. If material is not included in the article's Creative Commons licence and your intended use is not permitted by statutory regulation or exceeds the permitted use, you will need to obtain permission directly from the copyright holder. To view a copy of this licence, visit http://creativecommons.org/licenses/by/4.0/ The Creative Commons Public Domain Dedication waiver (http://creativecommons.org/publicdomain/zero/1.0/) applies to the data made available in this article, unless otherwise stated in a credit line to the data. 


\section{Background}

The long-acting reversible contraceptive (LARC) is a highly effective modern contraceptive method that includes an intrauterine contraceptive device (IUCD) and implants, which prevent unintended and closely spaced pregnancy [1]. Extended postpartum period LARC use refers to the initiation of IUCD or implants during the first 12 months of childbirth.

Globally, about 80 million unintended pregnancies occur during the postpartum period due to lower use of family planning [2]. In sub-Saharan African countries, $40 \%$ of unmet needs for family planning occur during the postpartum period [3]. The postpartum women LARC use has universally recognized several health benefits. LARC use reduces maternal and neonatal mortality and morbidity by preventing unintended pregnancy and unsafe abortion [4]. An individual couple delaying their next child at least 2 years and above can avert $30 \%$ of maternal and $10 \%$ of child mortality [5]. Published reports showed that a birth-to-pregnancy interval of above 2 years reduced prematurity, low birth weight, as well as small for gestational age [6]. In addition to health, FP has economic and social benefits for women, families, and the population at large. Family planning slowing the population growth, which aids the women to possess good income potential, dedicates enough for each child, resulting in reductions in poverty $[7,8]$.

Currently, family planning (FP) services incorporate into maternal and child health care services at all levels of the health care delivery system in Ethiopia. The government, local, and international partners on the FP program conducting maximal efforts to reach all over the country. The health extension workers intensively deliver the FP service to rural communities at health posts. [9]. Despite the above effort done, the Ethiopian demographic health survey (EDHS) 2016 reported only 7.1\% of women utilized LARC, which was far from the global FP target 2030 [10]. A cross-sectional study in Hossana (36.5\%) and Durame town (36.7\%) of women were using long-acting reversible contraceptives during the extended postpartum period, which was higher than the national magnitude [11, 12].

Many previous studies identified factors influencing the poor uptake of the long-acting reversible modern postpartum contraceptive use in Ethiopia. Sociodemographic factors like age, level of education, marital status, and religion significantly affect LARC use $[11,12]$. Antenatal and postnatal Family Planning counseling, menses return, resumption of sexual intercourse, and other maternal and reproductive healthrelated factors influence LARC utilization [13, 14].

Even though many studies were conducted to assess modern contraceptive use, there is a scarcity of evidence about factors affecting long-acting reversible contraceptive use during the extended postpartum period at the community level in southern Ethiopia. Therefore, this study aimed to assess the use of long-acting reversible contraceptives and associated factors among women who gave birth in the last 12 months in Arba Minch town, Southern Ethiopia.

\section{Methods}

We conducted a community-based cross-sectional study design from October 1st to November 30th, 2019 in Arba Minch town. Arba Minch is the capital of the Gamo zone, southern nation nationalities peoples region, Ethiopia. Arba Minch Zuria woredas in the north, west, and south and Nech-Sar National park in the east and some part of the northeast are the border of the town. The total area of the town is 4011hactare structured with 11 kebeles. Arba Minch town has a population of 112,724 , of which 56,137 (49.8\%) are males and 56,587 $(50.2 \%)$ are females. There is one General Hospital, three public health centers, and 11 health posts.

The source population of this study was all mothers who gave birth for the last 12 months before the study. The study population included sampled mothers who gave birth in the last 12 months before this study. The single population proportion formula was used to calculate the sample size. The assumption of $95 \%$ confidence level, 5\% margin of error and prevalence of Long-acting reversible contraception use which is 36.7\% (Durme town [15]) were considered. After adding a $20 \%$ nonresponse rate, the final computed sample size was 429 .

We identified all households who have a mother with a history of birth in the previous year using the family folder of the Health extension. The proportional number of study participants was allocated for each kebele. A lottery method was used to select the first postpartum woman. Then, the next postpartum woman was selected through a systematic random sampling of every Kth (3rd) interval household. In a case when the study participants could not interview, we attempted two times to interview the respondent, then we asked the next study participant. We used the lottery method when over one mother who gave birth in the last 12 months was found in the same house.

\section{Data collection instrument and procedure}

The data was collected by using a pre-tested structured questionnaire adapted from different literature, which was developed for similar purposes by different authors. The data collection tool (questionnaire) was prepared first in English and then translated to Amharic, which was translated back to English to ensure consistency. We used the Amharic version of data collection. The questionnaire comprises socioeconomic and demographic characteristics, reproductive history and maternal health care, knowledge, and current practice of long-acting reversible contraceptives during the extended postpartum period. 
Table 1 Frequency distribution of postpartum women by their background characteristics in Arba Minch town, 2019(N=416)

\begin{tabular}{|c|c|c|}
\hline Variable & Number(n) & Percent (\%) \\
\hline \multicolumn{3}{|l|}{ Age } \\
\hline$\leq 24$ & 92 & 22.2 \\
\hline $25-34$ & 276 & 66.3 \\
\hline$\geq 35$ & 48 & 11.5 \\
\hline \multicolumn{3}{|l|}{ Marital status: } \\
\hline Married & 392 & 94.2 \\
\hline Other* & 24 & 5.8 \\
\hline \multicolumn{3}{|l|}{ Women education } \\
\hline No formal education & 67 & 16.1 \\
\hline Primary & 122 & 29.3 \\
\hline Secondary & 110 & 26.4 \\
\hline Diploma and above & 117 & 28.2 \\
\hline \multicolumn{3}{|c|}{ Partner education $(N=392)$} \\
\hline No formal education & 26 & 6.6 \\
\hline Primary & 77 & 19.7 \\
\hline Secondary & 133 & 33.9 \\
\hline Diploma and above & 156 & 39.8 \\
\hline \multicolumn{3}{|l|}{ Ethnicity } \\
\hline Gamo & 229 & 55.1 \\
\hline Gofa & 37 & 8.9 \\
\hline Wolayita & 35 & 8.4 \\
\hline Amhara & 68 & 16.3 \\
\hline Oromo & 25 & 6.0 \\
\hline Others ${ }^{* *}$ & 22 & 5.3 \\
\hline \multicolumn{3}{|l|}{ Occupation } \\
\hline Housewife & 105 & 25.2 \\
\hline Self-employed & 110 & 26.4 \\
\hline Gov't employed & 103 & 24.8 \\
\hline Merchant & 54 & 13.0 \\
\hline Others ${ }^{* *}$ & 44 & 10.6 \\
\hline \multicolumn{3}{|l|}{ Religion } \\
\hline Protestant & 193 & 46.4 \\
\hline Orthodox & 191 & 45.9 \\
\hline Others*** & 32 & 7.7 \\
\hline \multicolumn{3}{|l|}{ Monthly income } \\
\hline$\leq 1000$ & 85 & 20.4 \\
\hline $1001-2000$ & 81 & 19.5 \\
\hline $2001-3000$ & 99 & 23.8 \\
\hline$>3000$ & 151 & 36.3 \\
\hline
\end{tabular}

Other *: Single, Divorced, Widwoid; Other**: Gurage, Tigre, Konso; Others** ${ }^{*}=$ Daily laborer, Unemployed; Others ${ }^{* * *}$ : Muslim, Catholic
Two diploma midwives and two clinical nurses collected data. One BSc midwife supervisor the interview. We trained the interviewers for one day before the actual data collection. Lecturing, mock interviews, and actual field practice were used to train the data collectors. The interview was done under close supervision. Interviewer-administered questionnaires via face-to-face interviews were used for data collection.

\section{Data processing and analysis}

All filed questioners were cheeked for completeness, consistency, and accuracy. The data was entered into Epi-Data version 4.6 and exported to the statical package of social science (SPSS) version 25 for further analysis.

Descriptive analyses (frequency, mean, percentage) were carried out for the variables. A Binary logistic regression was used to determine the relationship between the outcome and each independent variable. Those variables having a $P_{-}$ value of 0.25 and less in the bivariate analysis were added in the multivariable logistic regression analysis. HosmerLemeshow goodness of fit test was used to check the fitness of the model, which did not have a statically significant $p$ value of 0.183 . The adjusted odds ratio along with $95 \%$ of confidence interval was an estimate to identify factors associated with the outcome variable. The level of statistical significance was declared at a $p$-value less than 0.05 . The results are finally presented in tables, graphs, and text.

\section{Result}

Socio-demographic characteristics of the respondent A total of 416 postpartum women participated with a response rate of $96.96 \%$. The age of women ranges from 17 to 45 , with a mean age of 28.2 ( $\mathrm{SD} \pm 4$. 951) years.

Table 2 Distribution of postpartum women by reproductive health-related characteristics, Arba Minch town, 2019( $n=416)$

\begin{tabular}{lll}
\hline Variable & Frequency (n) & Percent (\%) \\
\hline Resumed Menses & 234 & 56.2 \\
$\quad$ Yes & 182 & 43.8 \\
$\quad$ No & & \\
Resumed Sexual Intercourse & 314 & 75.5 \\
$\quad$ Yes & 102 & 24.5 \\
No & & \\
Future Fertility Desire & 343 & 82.5 \\
Yes & 73 & 17.5 \\
No & & \\
Postpartum period (wk.) & 109 & 26.2 \\
0-12 & 173 & 41.6 \\
13-26 & 97 & 23.3 \\
27-38 & 37 & 8.9 \\
39-50 & & \\
\hline
\end{tabular}


Table 3 Distribution of postpartum women by Maternal healthrelated factors, Arba Minch town, 2019 $(n=416)$

\begin{tabular}{lll}
\hline Variable & Frequency & Percent \\
\hline ANC Follow Up & & \\
No ANC follow up & 30 & 7.2 \\
$\quad$ 4 Visits & 218 & 52.4 \\
4 and above visits & 168 & 40.4 \\
PNC Follow Up: & & \\
$\quad$ Yes & 126 & 30.3 \\
No & 290 & 69.7 \\
FP Counseling on ANC and PNC & & \\
Yes & 242 & 58.2 \\
No & 174 & 41.8 \\
\hline
\end{tabular}

Three hundred ninety-two women (94.2\%) were married (Table 1).

\section{Reproductive health-related characteristics of the study population}

The median number of living children was 2.44 per woman. One hundred thirty-three $(32.1 \%)$ had only one child. Seventy-three $(17.5 \%)$ did not wish to have more children in the future. Three hundred fourteen (75.5\%) of them had resumed sexual intercourse (Table 2).

\section{Maternal health-related factors of the study population} The study indicated that women who had four or more ANC visits were 168 (40.4\%). One-third (30.3\%) of the respondents had a post-natal visit within $24 \mathrm{~h}$. Two hundred forty-two (58.2\%) women had family planning counseling during ANC and PNC (Table 3).
Male partner involvement related factors of the study population

Two hundred eighty-five postpartum women discuss with their partner. On the other hand, $68 \%$ of postpartum are supported by their partner to use the modern contraceptive.

Knowledge and media exposure about contraceptive Knowledge of at least one modern contraceptive is 98.1\%. About the attitudes of the respondents towards the benefits of modern contraceptive utilization about half $(50.7 \%)$ of them had positive attitudes. One hundred eighty-three $(44.0 \%)$ postpartum women had got information from the media.

Long-acting reversible contraceptive use in the extended postpartum period

The prevalence of long-acting contraceptive utilization was found to be 94 (22.6\%). Seventy-seven respondent used (82\%) followed by IUCD 17(18\%) (Fig. 1).

Factors associated with postpartum long-acting reversible contraceptive utilization

In the multivariable logistic regression analysis, women's age, being married, menses resumption, sexual intercourse resumption, and got family planning counseling showed a significant association with postpartum LARC use.

Maternal age $\leq 24$ years $(\mathrm{AOR}=3.7,95 \% \mathrm{CI}: 1.5,8.9)$, being married $(\mathrm{AOR}=3.5(1.17-10.28))$ menses resumption $(\mathrm{AOR}=4.9$ 95\% CI: $(2.92,8.20))$, sexual intercourse resumption $(\mathrm{AOR}=7.1$ 95\% CI: $(4.03,12.56))$ times more likely to use postpartuim LARC compered to their counterpart.

\section{Type of long acting reversible contraceptive utilization}

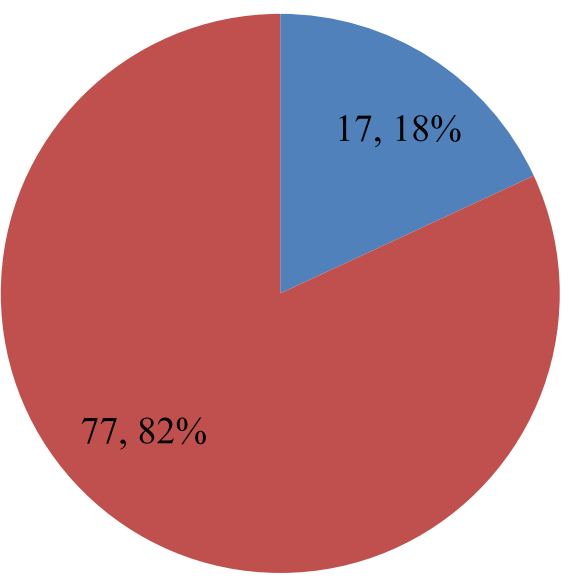

- IUCD

- Implant

Fig. 1 Magnitude of long-acting reversible contraceptive use by type of contraceptive among postpartum women in Arba Minch town, 2019(N=94) 
The study also indicated that postpartum women who were counseled about postpartum family planning were 3.2 times more likely to use LARC than those who did not counsel $[\mathrm{AOR}=3.295 \%(1.95,5.28)]$ (Table 4).

\section{Discussion}

This community-based research aimed to identify longacting reversible contraceptives use and associated factors in Arba Minch town among women in the extended postpartum period. The overall prevalence of longacting reversible contraceptive use was $22.5 \%$ during the extended postpartum period. This finding was higher

Table 4 Factors associated with long-acting reversible contraceptive use during the extended postpartum period, Ariba Minch town, $2019(n=416)$

\begin{tabular}{|c|c|c|c|}
\hline Variable & COR $(95 \% \mathrm{Cl})$ & AOR $(95 \% \mathrm{Cl})$ & $P$ value \\
\hline \multicolumn{4}{|l|}{ Age of the women } \\
\hline $15-24$ & $2.39(1.17-4.87)$ & $3.70(1.52-8.91)$ & 0.004 \\
\hline $25-34$ & $3.15(1.68-5.90)$ & $3.10(1.44-6.68)$ & 0.004 \\
\hline$\geq 35$ & 1.00 & & \\
\hline \multicolumn{4}{|l|}{ Marital status } \\
\hline Married & $3.99(1.66-9.55)$ & $3.50(1.17-10.28)$ & 0.025 \\
\hline Others* & 1.00 & & \\
\hline \multicolumn{4}{|l|}{ Women Education: } \\
\hline No formal education & 1.00 & & \\
\hline Primarily & $1.42(.778-2.61)$ & & \\
\hline Secondary & $1.63(0.87-3.31)$ & & \\
\hline Diploma and above & $2.29(1.22-4.29)$ & & \\
\hline \multicolumn{4}{|l|}{ ANC Visits } \\
\hline No visit & 1.00 & & \\
\hline$<4$ visits & $2.31(1.06-5.02)$ & & \\
\hline 4 and above & $4.36(1.94-9.79)$ & & \\
\hline \multicolumn{4}{|l|}{ Media Exposure } \\
\hline Yes & $2.63(1.71-4.03)$ & & \\
\hline No & 1.00 & & \\
\hline \multicolumn{4}{|l|}{ PPFP Counseling } \\
\hline Yes & $4.00(2.61-6.11)$ & $3.20(1.95-5.28)$ & 0.0001 \\
\hline No & 1.00 & & \\
\hline \multicolumn{4}{|l|}{ Knowledge of PPFP } \\
\hline Good & $5.68(1.13-8.51)$ & & \\
\hline Poor & 1.00 & & \\
\hline \multicolumn{4}{|l|}{ Menses Resumed: } \\
\hline Yes & $4.41(2.87-6.68)$ & $4.9(2.92-8.20)$ & 0.0001 \\
\hline No & 1.00 & & \\
\hline \multicolumn{4}{|c|}{ Sexual Intercourse resumed: } \\
\hline Yes & $6.73(4.12-11.01)$ & $7.10(4.03-12.56)$ & 0.0001 \\
\hline No & 1.00 & & \\
\hline
\end{tabular}

Other*: single, divorced, widowed than the national figure(7.1\%) [16]. This may be justified by increased access to and inclusive sexual reproductive health services for the past 4 years.

The finding from Hosanna (36.5\%) and Durame (36.7\%) town were higher than this study $[15,17]$. The reason for this difference might be due to the sample size, the residence of study participants, and access to information about family planning.

This study showed that postpartum women age less than 24 years were 3.7 times more likely to use LARC compared with women age 35 years and more. This finding is also supported by the study in Gondar Town, North West Ethiopia [18]. The possible reason may due to young women are more sexually active than older women.

This study also indicated that postpartum married women were three and half times more likely to use long-acting reversible contraceptives than others. This is consistent with the study done at Debre Tabor and Addis Ababa [19, 20]. This might be due to that married women were living with their husbands. They might start regular sexual intercourse earlier than the nonmarried couples that may force to use contraceptives to program the birth of the next child.

Family planning counseling during ANC and PNC was found to be associated with long-acting reversible contraceptive use during the extended postpartum period. Women who had received postpartum family planning counseling during ANC and PNC were 3.2 times more likely to use long-acting reversible contraceptives in the extended postpartum period than their counterparts. This result is agreed with Axum, north Ethiopia, and Malawi [12, 21]. This may be because women who have received family planning counseling during ANC and PNC might be highly motivated for LARC use.

Mothers whose menses resumed were almost five times more likely to utilize long-acting reversible contraceptives. This is inconsistent with the kinds of literature done in Addis Ababa and Gondar [18, 20]. This is because postpartum women may be aware of their fertility returning when menses return. This could be due to postpartum women believed that a return of fertility only occurs along with the return of menses.

The other stronger factor for the need for family planning is the resumption of sexual intercourse. Women who have resumed sexual intercourse were almost seven times more likely to use LARC compared to counterparts. This finding is supported by a study done by Hosanna and Axum [11, 12]. This might be because women who resumed sexual activity have a fear of getting pregnant. Consequently; they seek contraception than those who had not resumed sex.

\section{Conclusion and recommendations}

The finding of this showed that the level of long-acting reversible contraceptive utilization in the extended 
postpartum period was low. Women's age, being married, menses resumption, resumption of sexual intercourse, and family planning counseling during ANC and PNC were significant factors associated with the longacting reversible contraceptive use. Therefore, health institutions should strengthen antenatal and postnatal counseling of postpartum family planning. Health workers also should provide advice and counseling for postpartum women that make them understand that fertility may precede the return of menses.

\begin{abstract}
Abbreviations
AOR: Adjusted odds ratio; EDHS: Ethiopian demographic health survey; Cl: Confidence interval; COR: Crude odds ratio; PPFP: Postpartum Family Planning; FP: Family Planning; HSDP: Health Sector Development Program;
\end{abstract} LARC: long-acting reversible contraceptive; WHO: World Health Organization

\section{Acknowledgments}

I would like to express my deepest appreciation to Arba Minch University, College of Health Sciences for their ethical approval letter. We would like to appreciate our data collectors, supervisors, questionnaire translators, and study participants; without them, the research would not be possible.

\section{Authors' contributions}

YM conceived the study, developed the proposal, carried out data collection, conducted the analysis, was involved in reviewing the manuscript and had full access to all the data in the study, and had final responsibility for the decision to submit for publication. AW also provided general guidance on overall study progress and participated in reviewing the proposal, reviewing the analysis, and participated in the final study document development. AW was involved in drafting and reviewing the manuscript. The author(s) read and approved the final manuscript.

\section{Funding}

This research work is funded by Arba Minch University research, community service, and industry linkage vice president office.

\section{Availability of data and materials}

Full data set and other materials relating to this study can be obtained from the corresponding author upon reasonable request.

\section{Declarations}

\section{Consent to publication}

Not applicable.

\section{Ethics approval and consent to participate}

Ethical clearance was obtained from an ethical clearance committee of Arba Minch University College of Medicine and Health Science. A permission letter was written to Arba Minch town health office administration to conduct the study and the other permission letter was also obtained from the Arba Minch town administration. After the purpose and objective of the study are informing, informed verbal consent was obtained from each study participant.

\section{Competing interests}

The authors declare that there is no financial and non-financial conflict of interest regarding the publication of this paper.

\section{Author details}

'Department of Midwifery, College of medicine and health sciences, Wolkite University, Wolkite, Ethiopia. ${ }^{2}$ Department of Midwifery, College of medicine and health sciences, Debre Tabor University, Debre Tabor, Ethiopia.
Received: 25 June 2021 Accepted: 26 August 2021

Published online: 06 September 2021

\section{References}

1. Programming strategies for postpartum family planning. WHO. 2013 [cited 2019]. Available from: https://www.who.int/reproductivehealth/publications/ family planning/ppfp strategies/en/

2. Bellizzi S, Mannava P, Nagai M, Sobel H. Reasons for discontinuation of contraception among women with a current unintended pregnancy in 36 low and middle-income countries. Contraception. 2020;101(1):26-33. https:// doi.org/10.1016/j.contraception.2019.09.006.

3. Khan MN, Harris ML, Shifti DM, Laar AS, Loxton D. Effects of unintended pregnancy on maternal healthcare services utilization in low-and lowermiddle-income countries: systematic review and meta-analysis. Int J Public Health. 2019;64(5):743-54. https://doi.org/10.1007/s00038-019-01238-9.

4. Kinney MV, Kerber KJ, Black RE, Cohen B, Nkrumah F, Coovadia H, et al. SubSaharan Africa's mothers, newborns, and children: where and why do they die? PLoS Med. 2010;7(6):e1000294. https://doi.org/10.1371/journal.pmed.1 000294

5. Ganatra B, Faundes A. Role of birth spacing, family planning services, safe abortion services and post-abortion care in reducing maternal mortality. Best Pract Res Clin Obstet Gynaecol. 2016;36:145-55. https://doi.org/10.101 6/j.bpobgyn.2016.07.008.

6. Bater J, Lauer JM, Ghosh S, Webb P, Agaba E, Bashaasha B, et al. Predictors of low birth weight and preterm birth in rural Uganda: findings from a birth cohort study. PLoS One. 2020;15(7):e0235626. https://doi.org/10.1371/journa I.pone.0235626.

7. Allison A, Basikoro EE. Why world vision supports healthy timing and spacing of pregnancies to improve maternal and child health: a faith-based perspective. Christian J Global Health. 2017;4(2):75-9. https://doi.org/10.1 5566/cjgh.v4i2.169.

8. Norton M, Chandra-Mouli V, Lane C. Interventions for preventing unintended, rapid repeat pregnancy among adolescents: a review of the evidence and lessons from high-quality evaluations. Glob Health Sci Pract. 2017:5(4):547-70.

9. Tigabu S, Demelew T, Seid A, Sime B, Manyazewal T. Access to and utilization of quality family planning services: challenges and opportunities in meeting FP2020 targets. IJHSR. 2016;6(1):424e33.

10. Csa I. Central statistical agency (CSA)[Ethiopia] and ICF. Ethiopia demographic and health survey. Addis Ababa, Ethiopia and Calverton, Maryland; 2016.

11. Gejo NG, Anshebo AA, Dinsa LH. Postpartum modern contraceptive use and associated factors in Hossana town. PLoS One. 2019;14(5):e0217167. https:// doi.org/10.1371/journal.pone.0217167.

12. Abraha TH, Teferra AS, Gelagay AA. Postpartum modern contraceptive use in northern Ethiopia: prevalence and associated factors. Epidemiol Health. 2017;39.

13. Ashebir W, Tadesse T. Associated factors of postpartum modern contraceptive use in Burie District, Amhara region, Ethiopia. J Pregnancy. 2020;2020.

14. Mengesha ZB, Worku AG, Feleke SA. Contraceptive adoption in the extended postpartum period is low in Northwest Ethiopia. BMC Pregnancy Childbirth. 2015;15(1):1-6.

15. Tamrie YE, Hanna EG, Argaw MD. Determinants of long acting reversible contraception method use among mothers in extended postpartum period, Durame town, southern Ethiopia: a cross sectional community based survey Health. 2015;7(10):1315-26. https://doi.org/10.4236/health.2015.710146.

16. Mansori K, Hanis SM, Shadmani FK. Postpartum modern contraceptive use in northern Ethiopia: prevalence and associated factors-methodological issues in this cross-sectional study. Epidemiol Health. 2017;39. https://doi. org/10.4178/epih.e2017019.

17. Woldu BF, Ermolo TL, Lemu LG, Gejo NG. Long-acting reversible contraception utilization and associated factors among women in extended postpartum period in Hossana town, southern Ethiopia: cross sectional study. Contracept Reprod Med. 2020;5(1):1-6.

18. Abera Y, Mengesha ZB, Tessema GA. Postpartum contraceptive use in Gondar town, Northwest Ethiopia: a community based cross-sectional study. BMC Womens Health. 2015:15(1):1-8.

19. Taye EB, Mekonen DG, Debele TZ. Prevalence of post partum modern family planning utilization and associated factors among postpartum mothers in Debre Tabor town, north West Ethiopia, 2018. BMC Res Notes. 2019;12(1):1-7. 
20. Gebremedhin AY, Kebede Y, Gelagay AA, Habitu YA. Family planning use and its associated factors among women in the extended postpartum period in Addis Ababa, Ethiopia. Contracept Reprod Med. 2018;3(1):1-8. https://doi.org/10.1186/s40834-017-0054-5.

21. Bwazi C, Maluwa A, Chimwaza A, Pindani M. Utilization of postpartum family planning services between six and twelve months of delivery at Ntchisi District hospital, Malawi. Health. 2014;6(14):1724-35. https://doi.org/1 0.4236/health.2014.614205

\section{Publisher's Note}

Springer Nature remains neutral with regard to jurisdictional claims in published maps and institutional affiliations.

Ready to submit your research? Choose BMC and benefit from:

- fast, convenient online submission

- thorough peer review by experienced researchers in your field

- rapid publication on acceptance

- support for research data, including large and complex data types

- gold Open Access which fosters wider collaboration and increased citations

- maximum visibility for your research: over $100 \mathrm{M}$ website views per year

At $\mathrm{BMC}$, research is always in progress.

Learn more biomedcentral.com/submissions 